\title{
INCIDENCE OF VAGINAL CANDIDIASIS IN LEUCORRHOEA PATIENTS IN K. G. H.
}

\author{
S. Jhansi Lakshmi1, T. Santhi², P. Guru Prasad ${ }^{3}$, G. Lavanya ${ }^{4}$ \\ ${ }^{1}$ Assistant Professor, Department of Dermatology, Venereology and Leprosy, Andhra Medical College. \\ ${ }^{2}$ Assistant Professor, Department of Dermatology, Venereology and Leprosy, Andhra Medical College. \\ ${ }^{3}$ Associate Professor, Department of Dermatology, Venereology and Leprosy, Andhra Medical College. \\ ${ }_{4}^{4}$ Post Graduate, Department of Dermatology, Venereology and Leprosy, Andhra Medical College.
}

\section{ABSTRACT}

\section{BACKGROUND}

Candida is the most common agent causing leucorrhoea affecting the women of all strata. It is becoming difficult to completely eradicate the infection mainly due to recurrence caused by non-albican species of Candida. Most of the non-albican species of Candida are resistant to commonly used antifungal agent - azole. Therefore, studying the incidence of Candida species in vaginal secretion is of great significance.

\section{OBJECTIVE}

To study the incidence of Candidiasis in patients with leucorrhoea and identification of different species of Candida found in leucorrhoea patients. To know the candidal infection in relation to age of the woman, pregnancy, usage of antibiotics and steroids, economical status of the patients who attended the OPD of STD and Gynecology and Obstetrics Department, King George Hospital, Visakhapatnam, Andhra Pradesh, India.

\section{MATERIALS AND METHODS}

The study was conducted on 100 patients with specific complaints of leucorrhea. Discharge was examined by direct wet preparation by KOH mount, Gram staining, and Culture on Sabouraud's Dextrose Agar. Species differentiation was done by Germ Tube Formation, Sugar Assimilation and Sugar Fermentation test.

\section{RESULTS}

Candida infection with highest incidence (46.7\%) seen in women of age (21-30 years). Incidence of candidiasis was higher in pregnant (57.5\%) compared to non-pregnant (16.6\%). Candida albicans was the most common strain identified and Candida Krusei was the least common in our study.

\section{CONCLUSION}

Highest incidence was found between 21-30 years age group. In pregnant and women from low economic status was found highest incidence. Among Candida species, C. albicans was commonest followed by C. glabrata, C. tropicalis, C. krusei.

\section{KEYWORDS}

Candida, Candidiasis, Leucorrhoea.

HOW TO CITE THIS ARTICLE: S. Jhansi Lakshmi, T. Santhi, P. Guru Prasad, G. Lavanya, P. Anusha, S. Jahnavi, Ch. Sravya, V. Sri Lakshmi8. "Incidence of Vaginal Candidiasis in Leucorrhoea Patients in K. G. H." Journal of Evolution of Medical and Dental Sciences 2015; Vol. 4, Issue 98, December 07; Page: 16372-16374, DOI: 10.14260/jemds/2015/2420

\section{INTRODUCTION}

Candidiasis is the infection caused by species of Candida. The infection can be acute or chronic, superficial or deep and its clinical spectrum is so wide that a more specific definition cannot be made. ${ }^{1}$ Increasing literature on infection shows no sign of narrowing the clinical and scientific interest in Candida infection, which remains high. ${ }^{2}$ Data of incidence of vaginal candidiasis suggest approximately two-thirds of women experience at least one episode during their lifetime and nearly $50 \%$ of women have multiple episodes.

The majority of cases of vulvovaginal candidiasis are caused by C. albicans; however, incidences due to nonalbicans species of Candida appear to be increasing. ${ }^{3}$

\section{Financial or Other, Competing Interest: None.}

Submission 07-11-2015, Peer Review 08-11-2015,

Acceptance 25-11-2015, Published 07-12-2015.

Corresponding Author:

S. Jhansi Lakshmi,

Do. No. 16-5-7, Official Colony,

Maharani peta-530002,

Visakhapatnam.

E-mail: drsjhansilakshmi@gmail.com

DOI:10.14260/jemds/2015/2420

\section{MATERIALS AND METHODS}

A total of 100 patients having symptoms of Leucorrhoea attending the OPD of STD and Obstetrics and Gynecology Department of King George Hospital, Visakhapatnam, were included.

\section{Specimen Collection}

Specimens were collected with sterile cotton swab from the vagina or cervix avoiding the contamination of other organisms. The set of two swabs were collected for each specimen. Out of that one was subjected for direct smear examination and other was inoculated on Sabouraud's Dextrose Agar and incubated at $25^{\circ} \mathrm{C}$ and $37^{\circ} \mathrm{C}$ aerobically. Direct smear examination was done by $10 \% \mathrm{KOH}$ preparation and Gram staining.

\section{Identification}

The growth of Candida on Sabouraud's Dextrose Agar was confirmed by Gram staining, in which gram positive budding fungal cells were observed. Then its growth was examined for colony morphology on Sabouraud's Dextrose Agar and chlamydospore production on Cornmeal tween 80 agars. Germ tube tests and other biochemical tests like sugar 
fermentation, sugar assimilation and urease test were performed to identify the species of Candida.

\section{RESULTS}

Out of the 100 women, 42 were positive for vaginal candidiasis. Incidence of vaginal candidiasis higher in age group 21-30 (46.7\%) followed by 41-50 (40\%), and zero incidence was found in age group above 50 year. [Table-1] Incidence of vaginal candidiasis was higher in pregnant (57.5\%) than non-pregnant (39\%) patients. [Table-2]. Incidence of candidiasis was higher in women using antibiotics and steroids than non users. [Table-3].

Incidence of candidiasis was higher in low socioeconomic status (44.5\%) than higher status (12.5\%). Species wise distribution of the isolates was also studied. C. albicans was the most common isolate, having incidence of (78.57\%), followed by C. glabrata $(11.90 \%)$ and C. tropicalis (07.14\%) and C. krusei (02.38\%). [Table-4].

\begin{tabular}{|c|c|c|c|}
\hline Age & $\begin{array}{c}\text { Total } \\
\text { Leucorrhoea } \\
\text { Patients }\end{array}$ & $\begin{array}{c}\text { Candida } \\
\text { Positive } \\
\text { Patients }\end{array}$ & Percent \\
\hline $11-20$ & 32 & 13 & 38.2 \\
\hline $21-30$ & 45 & 21 & 46.7 \\
\hline $31-40$ & 17 & 6 & 33.3 \\
\hline $41-50$ & 5 & 2 & 40.0 \\
\hline 51 and above & 1 & - & \\
\hline Total & $\mathbf{1 0 0}$ & $\mathbf{4 2}$ & \\
\hline \multicolumn{4}{|c|}{ Table 1: Incidence of Vaginal Candidiasis } \\
in Relation to Age \\
\hline
\end{tabular}

\begin{tabular}{|c|c|c|c|}
\hline & $\begin{array}{c}\text { Total } \\
\text { Number } \\
\text { Patients }\end{array}$ & $\begin{array}{l}\text { Candida } \\
\text { Positive } \\
\text { Patients } \\
\end{array}$ & Percent \\
\hline Pregnant & 14 & 8 & 57.5 \\
\hline Non-pregnant & 86 & 34 & 39 \\
\hline Total & 100 & 42 & \\
\hline
\end{tabular}

\begin{tabular}{|c|c|c|c|}
\hline & $\begin{array}{c}\text { Number } \\
\text { of Patients }\end{array}$ & $\begin{array}{c}\text { Candida } \\
\text { Positive } \\
\text { Patients }\end{array}$ & Percent \\
\hline Antibiotics used & 12 & 2 & 16.7 \\
\hline Steroids & 7 & 1 & 14.3 \\
\hline
\end{tabular}

Table 3: Incidence of Vaginal Candidiasis in Relation to Usage of Antibiotics and Steroids

\begin{tabular}{|c|c|c|}
\hline Name of Species & Number of Patients & Percent \\
\hline C. albicans & 33 & 78.57 \\
\hline C. glabrata & 5 & 11.90 \\
\hline C. tropicalis & 3 & 7.14 \\
\hline C. krusei & 1 & 2.38 \\
\hline Total & 42 & \\
\hline
\end{tabular}

\section{DISCUSSION}

Vaginal candidiasis is common opportunistic mucosal infection caused predominantly by C. albicans, which affects a significant number of otherwise healthy women of childbearing age. Vaginal candidiasis is one of the common infections of General Practice, second only to anaerobic bacterial vaginosis. About three quarter of all women suffer at least one episode of this condition during their lifetime. Incidence of vaginal candidiasis reported by different workers show the rate of $(9.5 \%) .{ }^{4} ;(16.5 \%) .{ }^{5}$ and $(21.31 \%) .{ }^{6}$ In present study, we found $42 \%$ incidence of vaginal candidiasis. In the present investigation, $46.7 \%$ of women with leucorrhea were of the age $21-30$ and $33.3 \%$ were in the age group of 31-40 years, which was comparable with other study like Nandan et al. ${ }^{5}$, Field PL. ${ }^{7}$ and Nwokolo NC. ${ }^{8}$ Ovarian activity as well as sexual activity is maximum in women of 20-30 years age. During this period, the ovary produces adequate amount of estrogen, which favors the Candida growth by maintaining the acidic $\mathrm{pH}$ and enhancing the yeast adherence to vaginal epithelial cells. ${ }^{9}$ Incidence of vaginal candidiasis was remarkably higher during pregnancy due to physiological changes. Sobel has reported incidence of symptomatic vaginal candidiasis high in pregnancy and increases during the course of gestation. ${ }^{10}$ In our study also similar findings were obtained. During pregnancy, elevated level of reproductive hormones like estrogen increases the vaginal glycogen content that acts as a carbon source for the growth of Candida species. ${ }^{11}$ In our study, $78.57 \%$ of women with leucorrhea were harboring C. albicans. However, we also observed a concomitant increase in the prevalence of nonalbicans species in our study. Among the non-albicans species, C. glabrata was the most common type (11.90\%) and C. krusei was the least common type (2.38\%). Previous studies have shown that $\mathrm{C}$. glabrata is one of the major causes for recurrent vulvovaginal candidosis. Vaginitis induced by non-albicans species is clinically indistinguishable from that caused by C. albicans. ${ }^{12}$ The explanation for increase in the incidence of vulvovaginal candidosis caused by non-albicans strains is thought to be because of single-dose treatment, low-dosage azole maintenance regimens and the use of over prescription of antimycotics. ${ }^{13}$ Therefore for effective control of candidiasis, it is advisable to identify the Candida species before planning the treatment.

\section{CONCLUSION}

In conclusion, highest incidence of candidiasis in patient of leucorrhoea found in age group of 21-30 years. Incidence was higher in pregnants. Women using antibiotics and steroids and from lower socioeconomic class (44.5\%) show higher incidence. Among the candida species most frequent isolate was C. albicans $(78.57 \%)$ followed by C. glabrata $(11.90 \%)$ and C. tropicalis $(7.14 \%)$ and C. krusei $(2.38 \%)$. For effective treatment of the infection, to prescribe the correct medication and to overcome the recurrence, it may be advisable to identify the Candida species routinely from vaginal swabs of infected women.

\section{REFERENCES}

1. Kwon Chung KJ and Bennett JE: Medical Mycology. Lea \& Febiger, Philadelphia 1992.

2. Odds FC: Candida and Candidosis. Baillier Tindall, London. 1988.

3. Richter SS, Galask RP, Messer AS, Hollis RJ, Diekema DJ, Pfaller MA: J Clin Microbiol 2005, 43: 2155-2162.

4. Mahadani JW, et al.: Diagnosis of discharge per vaginum, Indian J, Patho Microbial 1998 oct. 41 (4) 403-11.

5. Nanadan, et al.: Reproductive tract infection in women of reproductive age group in Sitapur of UP. Indian J Pub Health 2011; Jan-Mar. 45(1): 8-13.

6. Joshi BK, et al.: Incidence of VC and TV in leucorrhoea 1983. 
7. Field PL, et al.: effect of reproductive hormone on VC, inf Immunity 2000; Feb. 68(2):651-7.

8. Nwokolo $\mathrm{NC}$, et al.: chronic vaginal candidiasis and management in menopausal women: drug ageing 2002; May 16(5):335-9.

9. Donald I. Aetiology and investigation of vaginal discharge. Br Med J 1952;2:1223-6.

10. Sobel, JD: Am J Obste Gynecol 152:924- 935 (1985).

11. Davidson F, Oates JK. The pill does not cause 'thrush.' Br J Obstet Gynaecol 1985;92:1265.
12. Bauters TG, Dhont MA, Temmerman MI, Nelis HJ. Prevalence of vulvovaginal candidiasis and susceptibility to fluconazole in women. Am J Obstet Gynecol 2002;187:569-74.

13. Cauwenbergh G. Vaginal candidiasis: Evolving trends in the incidence and treatment of non-Candida albicans infection. Curr Probl Obstet Gynecol Fertil 1990;8:241. 